Braz J Med Biol Res, September 2012, Volume 45(9) 869-874

doi: 10.1590/S0100-879X2012007500095

Evaluation of hemostatic changes using thromboelastography after crystalloid or colloid fluid administration during major orthopedic surgery

I. Topçu, M. Çivi, T. Öztürk, G.T. Keleş, S. Çoban, E.A. Yentür and G. Okçu

The Brazilian Journal of Medical and Biological Research is partially financed by

\section{Q}

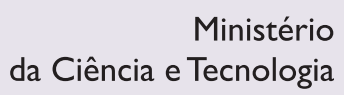

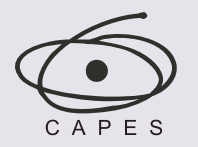

Ministério da Educação
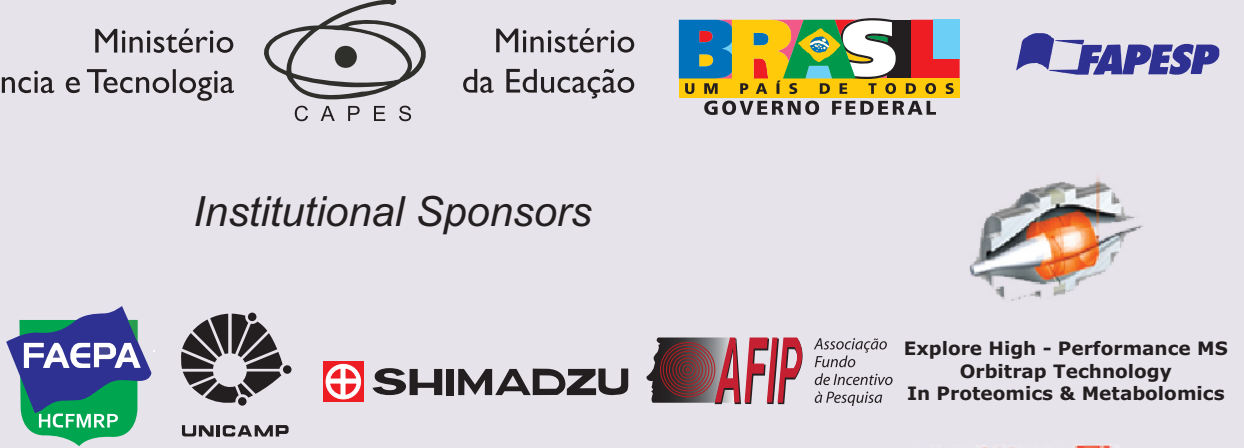

Institutional Sponsors

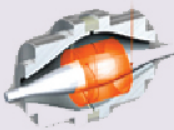

$\oplus$ SHIMADZU UNICAMP

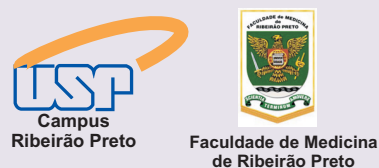
de Ribeirão Preto 


\title{
Evaluation of hemostatic changes using thromboelastography after crystalloid or colloid fluid administration during major orthopedic surgery
}

\author{
I. Topçu ${ }^{1}$, M. Çivi ${ }^{1}$, T. Öztürk¹ ${ }^{1}$, G.T. Keleş${ }^{1}$, S. Çoban¹, \\ E.A. Yentür ${ }^{1}$ and G. Okçu ${ }^{2}$ \\ ${ }^{1}$ Department of Anesthesiology and Reanimation, \\ Faculty of Medicine, Celal Bayar University, Manisa, Turkey \\ ${ }^{2}$ Department of Orthopedics and Traumatology, \\ Faculty of Medicine, Celal Bayar University, Manisa, Turkey
}

\begin{abstract}
The effects of Ringer lactate, $6 \%$ hydroxyethyl starch (130/0.4) or 4\% succinylated gelatin solutions on perioperative coagulability were measured by thromboelastography (TEG). Seventy-five patients (ASA I-III) who were to undergo major orthopedic procedures performed under epidural anesthesia were included in the study. Patients were randomly divided into three groups of 25 each for the administration of maintenance fluids: group RL (Ringer lactate), group HES (6\% hydroxyethyl starch 130/0.4), and group JEL (4\% gelofusine solution). Blood samples were obtained during the perioperative period before epidural anesthesia (t1, baseline), at the end of the surgery (t2), and $24 \mathrm{~h}$ after the operation (t3). TEG data, reaction time (R), coagulation time (K), angle value $(\alpha)$, and maximum amplitude (MA) were recorded. TEG parameters changed from normal values in all patients. In group $\mathrm{RL}, \mathrm{R}$ and $\mathrm{K}$ times decreased compared to perioperative values while the $\alpha$ angle and $\mathrm{MA}$ increased $(\mathrm{P}<0.05)$. In group HES, $R$ and $K$ times increased, however, the $\alpha$ angle and MA decreased $(P<0.05)$. In group JEL, $R$ time increased $(P<0.05)$, but $\mathrm{K}$ time, $\alpha$ angle and MA did not change significantly. In the present study, RL, $6 \%$ HES (130/0.4) and $4 \%$ JEL solutions caused changes in the coagulation system of all patients as measured by TEG, but these changes remained within normal limits.
\end{abstract}

Key words: Hydroxyethyl starch; Ringer lactate; Gelatin; Coagulation; Thromboelastography; Orthopedic surgery

\section{Introduction}

Intraoperative fluids are given for compensatory intravascular volume expansion, replacement of lost fluids and third space losses, and as maintenance fluids. Since hypovolemia may cause organ dysfunction leading to death, it deserves our utmost attention (1,2). Any delay in replacing intravascular volume may damage systemic hemodynamics, microvascular flow, and ultimately organ function. Administration of iv fluids during the intraoperative period in order to optimize stroke volume, particularly in orthopedic and abdominal surgery patients, has decreased postoperative complications and length of hospitalizations $(3,4)$. Crystalloid and colloid solutions and combinations thereof can be given as volume replacement for hypovolemia. Colloid fluids are more effective in correcting intravascular volume and microcirculation deficits than crystalloid solutions $(5,6)$.

Coagulopathy may develop in patients who have undergone major surgery or trauma, even in those without coagulation disorders. This can occur through loss of blood, loss of coagulation factors, consumption of platelets, and iv fluid replacement (7). Hypercoagulability has developed with the use of crystalloids and hypocoagulability with the use of colloids from iv volume resuscitation fluids used in major surgeries $(8,9)$. Gelatin solutions are able to form a basis for coagulopathy through hemodilution, hydroxyethyl starch (HES) solutions both by hemodilution and by damaging the interaction between fibrin and platelets $(10,11)$.

Thromboelastography ${ }^{\circledR}\left(\right.$ TEG $\left.^{\circledR}\right)$ is a tool capable of monitoring all phases of hemostasis by using whole blood

Correspondence: I. Topçu, Department of Anesthesiology and Intensive Care, Faculty of Medicine, Celal Bayar University, Manisa, Turkey. Fax: +90-236-237-0213. E-mail: topcuismet@yahoo.com

Received December 14, 2011. Accepted May 21, 2012. Available online June 8, 2012. Published August 17, 2012. 
as a test material $(12,13)$. The TEG system monitors both hemorrhagic and prothrombotic states. Platelets play a major role in hemostasis. Platelet mapping by TEG measures the effects of platelet-inhibiting drugs and shows platelet pathologies. TEG can determine the strength, durability and kinetics of the clot formed. While strength and durability determine whether or not a clot fulfills its role in hemostasis, kinetics indicates whether or not clot formation is sufficient in terms of quantitative factors. TEG permits the strength of blood coagulation to be measured in real time. Reaction time (R), coagulation time (K), $\alpha$ angle, and maximum amplitude (MA) are the parameters usually measured by TEG (Figure 1). Long $\mathrm{R}$ and $\mathrm{K}$ times and $\mathrm{a}$ low $\alpha$ angle and MA value indicate hypocoagulopathy, and short $R$ and $K$ times and high $\alpha$ angle and MA value indicate hypercoagulopathy (14).

In this study, we evaluated the effect of the crystalloid Ringer lactate $(\mathrm{RL})$ and the colloids 6\% HES (130/0.4) and $4 \%$ succinylated gelatin solutions on perioperative (major orthopedic procedures) coagulability changes as measured by TEG.

\section{Material and Methods}

The research protocol was approved by the university Ethics Committee. Adult patients (ASA I-III) upon which major orthopedic surgery was planned in our university medical center were approached for inclusion in the study. Those with malnutrition, hypoproteinemia, abnormal coagulation tests, and those taking anticoagulants, suffering from ischemic heart disease, liver or kidney failure were excluded from the study.

Patients were brought to the operating room without being premedicated. Maintenance fluid requirements were calculated according to the 4-2-1 rule defined by Holliday and Seger (15), and an infusion of RL solution was started at the appropriate rate. An epidural catheter was placed using the loss of resistance technique at L2-L3 or L3-L4, and bupivacaine was administered. An arterial cannula and central venous catheter were placed. Intraoperatively, heart rhythm (ECG), invasive and non-invasive arterial blood pressures, peripheral oxygen saturation $\left(\mathrm{SaO}_{2}\right)$, end-tidal carbon dioxide $\left(\mathrm{EtCO}_{2}\right)$, central venous pressure (CVP), and urine output were monitored. Pre-induction, post-induction and postoperative mean arterial pressure, heart rate, and CVP were recorded.

Patients were randomized using a computer-generated sequence of random numbers immediately before induction of anesthesia and assigned to one of three groups: group $\mathrm{RL}$ received $13-15 \mathrm{~mL} \cdot \mathrm{kg}^{-1} \cdot \mathrm{h}^{-1} \mathrm{RL}$ (Vacoliter ${ }^{\circledR}$, Eczacıbaş।Baxter, Turkey), group HES received $6-8 \mathrm{~mL} \cdot \mathrm{kg}^{-1} \cdot \mathrm{h}^{-1} 6 \%$ HES 130/0.4 (Voluven ${ }^{\circledR}$, Fresenius Co., Germany) and group JEL received $8-11 \mathrm{~mL}^{-1} \cdot \mathrm{kg}^{-1} \cdot \mathrm{h}^{-1} 4 \%$ gelofusine (Gelofusin ${ }^{\circledR}$, B. Braun Co., Germany) solutions. Fluid losses due to hunger were first calculated in all patients and the infusion was then regulated so that this quantity could be given within $3 \mathrm{~h}$. Normovolemia was obtained. The maximum dose of colloids permitted was $40 \mathrm{~mL} / \mathrm{kg}$. Blood loss was measured by monitoring blood accumulated in the aspirator and numbers of compresses used. Hematocrit was tracked during surgery and when the level of hemoglobin fell below $8 \mathrm{~g} / \mathrm{dL}$, blood was administered. Surgery times, volume of iv fluids given during surgery, urine output, and blood loss were recorded.

Blood samples for TEG were taken at baseline ( $\mathrm{t} 1$, before epidural anesthesia), at the end of surgery (t2), and $24 \mathrm{~h}$ postoperatively (t3). TEG analysis was done by an anesthesiologist blind to the study group of the patient using a Thrombelastograph ${ }^{\circledR} 5000$ coagulation analyzer (Haemonetics Corp., USA). The TEG tool was adjusted to perform measurements at $37^{\circ} \mathrm{C}$. One milliliter of citrated blood was shaken within a kaolin tube and then mixed. From this sample, $340 \mu \mathrm{L}$ blood was placed in a TEG tube with an automatic pipette and $20 \mu \mathrm{L}$ calcium was added in order to counteract the effect of citrate. A single-use piston covered with a plastic casing was dropped into the blood sample by means of a wire. The TEG tool was started and the following data were transmitted to a computer screen: $\mathrm{R}$ time (normal value: 3-8 $\mathrm{min}$ ), $\mathrm{K}$ time (normal value: 1-3 min), $\alpha$ angle (normal value: $55-78^{\circ}$ ), and MA (normal value 51-69 mm) (Figure 1). Pre- and 24-h postoperative prothrombin time and activated partial thromboplastin time values were also measured. Following surgery, patients were transferred to the postanesthesia care unit. Oxygen (4 L/min) was given by a nasal cannula and patients were

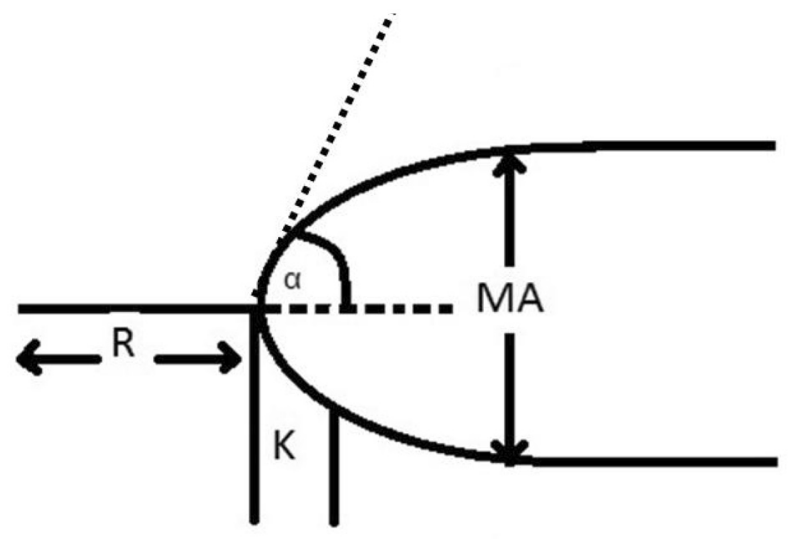

Figure 1. Definition of the thromboelastography $\left(T E G^{\circledR}\right)$ parameters. $R=$ time of latency from the time that the blood was placed in the TEG ${ }^{\circledR}$ analyzer until the initial formation of fibrin; $\alpha=$ value that measures the rapidity of fibrin build-up and cross-linking, i.e., the kinetics of clot strengthening; $\mathrm{K}=\mathrm{a}$ measure of the rapidity to reach a certain level of clot strength; $M A=$ maximum amplitude, a direct function of the maximum dynamic properties of fibrin and platelet bonding, which represents the ultimate strength of the fibrin clot. 
monitored for $24 \mathrm{~h}$. RL as maintenance fluid was given to all patients at the same rate as it was given during surgery. Postoperative analgesia was obtained using bupivicaine, fentanyl and patient-controlled epidural analgesia.

Statistical analyses were performed using SPSS for Windows ${ }^{\circledR} \mathrm{V} 14.0$ (SPSS, USA). Descriptive analyses (mean and standard deviation) were performed, as well as oneway ANOVA for inter-group comparisons of quantitative data and Tukey honestly significant difference (HSD) for the determination of the group responsible for the difference. The Kruskal-Wallis test was used for intergroup comparisons of data that were not normally distributed. The Mann-Whitney U-test was used in order to determine the group responsible for the difference. The paired sample $t$-test was used for "ingroup" comparison of normally distributed parameters and the Wilcoxon sign test was used for "in-group" comparison of non-normally distributed parameters. The chi-square test was used for qualitative data analysis. A value of $P<0.05$ was considered to be statistically significant.

\section{Results}

Seventy-five patients undergoing major lower extremity orthopedic surgery participated in the study (25 in each group). No differences in demographic or preoperative oxygen saturation values were detected. The numbers of knee and hip operations performed and operation times were similar for the three groups. The volume of intravenous perioperative fluid given was significantly greater in group $\mathrm{RL}(3.85 \pm 1.73 \mathrm{~L})$ than in group HES $(2.85 \pm 0.46 \mathrm{~L})$ and group JEL $(2.53 \pm 0.50 \mathrm{~L}, \mathrm{P}<0.05)$. However, the requirement for blood transfusion was similar among groups (Table 1). No differences in preoperative hematological laboratory values were found among groups (Table 2).

TEG results are shown in Table 3 . $R$ values in group $\mathrm{RL}$ immediately postoperatively and $24 \mathrm{~h}$ postoperatively were significantly lower than preoperative values $(P<0.05)$. $R$ values in group HES and group JEL were significantly higher immediately and $24 \mathrm{~h}$ postoperatively than in the preoperative period $(P<0.05)$.

$\mathrm{K}$ values in group $\mathrm{RL}$ immediately postoperatively and $24 \mathrm{~h}$ postoperatively were significantly lower than the preoperative values $(P<0.05)$. In groups HES and JEL, $K$ values immediately postoperatively and $24 \mathrm{~h}$ postoperatively were significantly higher than preoperative values (P < 0.05; Table 3).

TEG $\alpha$ angles in group RL immediately postoperatively and $24 \mathrm{~h}$ postoperatively were significantly higher than the preoperative values $(P<0.05)$. TEG $\alpha$ angles in group HES immediately postoperatively and $24 \mathrm{~h}$ postoperatively were significantly lower than the preoperative values $(P<$
Table 2. Preoperative laboratory values of patients receiving different maintenance fluids during orthopedic surgery.

\begin{tabular}{lccr}
\hline & Group RL & Group HES & \multicolumn{1}{c}{ Group JEL } \\
\hline PT $(\mathrm{s})$ & $11.42 \pm 0.94$ & $11.44 \pm 0.8$ & $11.28 \pm 0.51$ \\
aPTT $(\mathrm{s})$ & $25.17 \pm 2.98$ & $24.57 \pm 2.77$ & $23.76 \pm 2.86$ \\
HGB $(\mathrm{g} / \mathrm{dL})$ & $12.56 \pm 1.34$ & $12.22 \pm 1.47$ & $12.36 \pm 1.13$ \\
HTC $(\%)$ & $36.38 \pm 3.84$ & $34.55 \pm 3.2$ & $36 \pm 3.51$ \\
\hline
\end{tabular}

Data are reported as means \pm SD for 25 patients/group. There were no statistical differences among groups (ANOVA). RL = Ringer's lactate; HES $=6 \%$ hydroxyethyl starch (130/0.4); JEL $=4 \%$ succinylated gelatin; $\mathrm{PT}=$ prothrombin time; $\mathrm{aPTT}=\mathrm{ac}-$ tivated partial thromboplastin time; $\mathrm{HGB}=$ hemoglobin; $\mathrm{HTC}=$ hematocrit.

$0.05)$, but those of group JEL were not significantly different (Table 3).

MA in group RL immediately postoperatively and $24 \mathrm{~h}$ postoperatively were significantly higher than the preoperative values $(P<0.05)$. MA values in group HES immediately postoperatively and $24 \mathrm{~h}$ postoperatively were significantly lower than preoperative values $(P<0.05)$, but those of group JEL were not significantly different (Table 3).

\section{Discussion}

Hypercoagulability changes occurred in both in vitro and in vivo studies in which crystalloid solutions were used (16-18). These changes are thought to be caused by the disruption of balance between naturally circulating anticoagulants, activated procoagulants, and a decrease in antithrombin III (18). This effect decreases the positive feedback threshold of the intrinsic coagulation cascade, allowing coagulation to increase. This is the case with rapid infusions in patients with accompanying vascular disease (18). Colloids interrupt the increase in coagulation stimulated 
by the surgical insult, but changes in coagulation are more distinctive depending on changes caused by fluid administration (18). In other words, an increase in coagulation immediately occurs when crystalloid is given, even before the surgery has begun. On the other hand, when colloids are given, platelet aggregation is blocked (e.g., after HES administration) and coagulation strength decreases with antiplatelet activity (8).

In the present study, hypercoagulable changes in TEG parameters were observed with the administration of $\mathrm{RL}$, although values remained within normal limits. These results are similar to those reported by Ruttmann et al. (18) in a study of patients undergoing peripheral vascular surgery with epidural anesthesia. However, these investigators (18) did not find an increase in coagulation with colloids, and thought that perioperative coagulation changes were due to dilution rather than to the surgical stimulus. Martin et al. (16) evaluated thromboelastographic coagulation profiles during major surgery and discovered that hypercoagulability caused by $\mathrm{RL}$ continued into the postoperative period, in agreement with our findings. On the contrary, Butwick et al. (19) reported no changes in TEG parameters with $1500 \mathrm{~mL}$ $\mathrm{RL}$ given before regional anesthesia in caesarean delivery. As mentioned above, dilution is an important determinant of the effects of crystalloids on coagulation; thus our results differed from theirs due to the larger amount of fluid given to our patients.

Colloids are extremely effective volume expander solutions. However, the effects of synthetic colloid fluids on hemostasis are still unclear. Mardel et al. (20) reported that using gelatin-based products decreased clot quality by intervening in the polymerization of fibrin monomers and by decreasing fibronectin functions. Dextrans have more negative effects on coagulation than gelatins or HES (21). As measured by TEG, high molecular weight starches and dextrans weaken the usual hypercoagulability caused by surgery (22). The effects of colloids on blood coagulation depend on their molecular weight and rate of elimination (23).

In the present study, TEG parameters increased more (longer $\mathrm{R}$ and $\mathrm{K}$ times) in 6\% HES (130/0.4) patients than in the $4 \% \mathrm{JEL}$ group, but measurements remained within normal reference limits [HES group: $\mathrm{R}$ values $(\mathrm{t} 1=4.23$ $\pm 0.8, \mathrm{t} 2=4.85 \pm 1.52, \mathrm{t} 3=4.75 \pm 1.49), \mathrm{K}$ values $(\mathrm{t} 1=$ $1.44 \pm 0.38, \mathrm{t} 2=1.93 \pm 0.58, \mathrm{t} 3=2.24 \pm 1.21)$ and $\mathrm{JEL}$ group: $\mathrm{R}$ values $(\mathrm{t} 1=5.08 \pm 1, \mathrm{t} 2=5.33 \pm 1.18, \mathrm{t} 3=5.62$ $\pm 1.16), \mathrm{K}$ values $(\mathrm{t} 1=1.64 \pm 0.32, \mathrm{t} 2=1.87 \pm 0.78, \mathrm{t} 3=$ $1.97 \pm 0.91)$ ]. Butwick et al. (19) obtained similar results in their cesarean operations. In another study comparing postoperative JEL, 6\% HES (200/0.7), and albumin in cardiac surgery patients, clot formation time, $\alpha$ angle, and clot strength resulting from fibrinogen were disrupted with both HES (200/0.7) and JEL. However, the disruption was more pronounced with HES solution, but hemostatic parameters were not affected by albumin (24).
Table 3. Thromboelastography parameters of patients receiving various maintenance fluids.

\begin{tabular}{cccc}
\hline Parameter/time & Group RL & Group HES & Group JEL \\
\hline R (min) & & & \\
t1 & $5.79 \pm 1.34^{*}$ & $4.23 \pm 0.8^{*}$ & $5.08 \pm 1^{*}$ \\
t2 & $3.46 \pm 1.95^{\#}$ & $4.85 \pm 1.52$ & $5.33 \pm 1.18$ \\
t3 & $4.11 \pm 1.8$ & $4.75 \pm 1.49$ & $5.62 \pm 1.16$ \\
K (min) & & & \\
t1 & $1.96 \pm 0.66^{*}$ & $1.44 \pm 0.38^{*}$ & $1.64 \pm 0.32$ \\
t2 & $1.25 \pm 0.58^{\#}$ & $1.93 \pm 0.58$ & $1.87 \pm 0.78$ \\
t3 & $1.71 \pm 0.64$ & $2.24 \pm 1.21$ & $1.97 \pm 0.91$ \\
a angle & & & \\
t1 & $64.86 \pm 7.47^{*}$ & $65.04 \pm 4.84^{*}$ & $69.47 \pm 6.94$ \\
t2 & $76.20 \pm 7.28^{\#}$ & $62.14 \pm 6.32$ & $67.79 \pm 4.71$ \\
t3 & $70.54 \pm 7.73$ & $60.55 \pm 8.14$ & $67.84 \pm 4.83$ \\
MA (mm) & & & \\
t1 & $59.82 \pm 4.71^{*}$ & $63.02 \pm 5.68^{*}$ & $64.35 \pm 6.41$ \\
t2 & $67.08 \pm 5.77$ & $60.32 \pm 4.96$ & $63.03 \pm 6.24$ \\
t3 & $65.86 \pm 4.58$ & $60.90 \pm 6.19$ & $62.83 \pm 7.15$ \\
\hline
\end{tabular}

Data are reported as means $\pm \mathrm{SD}$ for 25 patients/group. $\mathrm{RL}=$ Ringer's lactate; HES = 6\% hydroxyethyl starch (130/0.4); JEL $=4 \%$ succinylated gelatin; $\mathrm{R}=$ reaction time; $\mathrm{K}=$ coagulation time; $\mathrm{MA}=$ maximum amplitude; $\mathrm{t} 1=$ baseline; $\mathrm{t} 2=$ at the end of surgery; $\mathrm{t} 3=24 \mathrm{~h}$ after surgery. ${ }^{*} \mathrm{P}<0.05$, compared to other times within groups; $\mathrm{AP}<0.05$, compared to $\mathrm{t} 3$ within groups (paired sample $t$-test).

In their study of TEG findings in three groups of knee replacement surgery patients $\left[R L, R L+4 \mathrm{~mL} \cdot \mathrm{kg}^{-1} \cdot \mathrm{h}^{-1} \mathrm{JEL}\right.$, $\mathrm{RL}+3 \mathrm{~mL} \cdot \mathrm{kg}^{-1} \cdot \mathrm{h}^{-1} 6 \%$ HES (200/0.5)], Innerhover et al. (25) found that both colloids resulted in significantly lower total clot strength compared to RL; they suggested that this was due to a decrease in the effectiveness of fibrinogen and to disruption of hemostasis by platelets. In the same study, fibronectin concentrations decreased more with RL than with HES and JEL solutions. Even though lower fibronectin concentrations contributed to the decreased clot strength resulting from colloids, clot strength in the study was affected similarly by both colloids (25). When 1500-2000 mL JEL, HES (130/0.4) or RL solutions were administered perioperatively to major orthopedic surgery patients, Mittermayr et al. (26) found the greatest decrease in a angle, clot formation time and fibrin polymerization with HES, a lower decrease with the JEL solution, and the least decrease with RL. In a study of abdominal surgery patients whose coagulation was evaluated following the administration of $4 \%$ JEL, $6 \%$ HES 70/05, or 6\% HES 200/0.5 (enough to keep the CVP between 10 and $14 \mathrm{mmHg}$ ), blood loss, requirement for blood transfusion, and thrombin and fibrin formation were similar in the three groups of patients, but factor VIII and von Willebrand factor levels increased more in the JEL group compared to the other groups (27). Thus, JEL and HES 
solutions can be safely used in major abdominal patients without causing coagulopathy.

The effects of $5 \%$ albumin and synthetic colloids $(6 \%$ HES (130/0.4) and 4\% JEL) on hemostasis were evaluated by Haas et al. (28) in pediatric patients undergoing surgery. They found that, in hemostatic terms, the JEL solution could be used as an excellent alternative to albumin for fluid replacement in pediatrics; the greatest effects on coagulability occurred with the HES solution (28). All colloids affect the coagulation system but, by using TEG, in vitro studies suggest that JEL solutions are less intrinsically anticoagulant than HES, whereas dextran has the most potent antithrombotic effects (29).

In the present study, RL solution was used as the basal and replacement fluid in group $R L$, thus the amounts of infused RL were high, as they were in other studies with

\section{References}

1. Mythen MG, Webb AR. Intra-operative gut mucosal hypoperfusion is associated with increased post-operative complications and cost. Intensive Care Med 1994; 20: 99-104.

2. Deane SA, Gaudry PL, Woods P, Cass D, Hollands MJ, Cook RJ, et al. The management of injuries - a review of deaths in hospital. Aust N Z J Surg 1988; 58: 463-469.

3. Sinclair S, James S, Singer M. Intraoperative intravascular volume optimisation and length of hospital stay after repair of proximal femoral fracture: randomised controlled trial. BMJ 1997; 315: 909-912.

4. Wakeling HG, McFall MR, Jenkins CS, Woods WG, Miles WF, Barclay GR, et al. Intraoperative oesophageal Doppler guided fluid management shortens postoperative hospital stay after major bowel surgery. Br J Anaesth 2005; 95: 634642.

5. Norberg A, Brauer KI, Prough DS, Gabrielsson J, Hahn RG, Uchida $T$, et al. Volume turnover kinetics of fluid shifts after hemorrhage, fluid infusion, and the combination of hemorrhage and fluid infusion in sheep. Anesthesiology 2005; 102: 985-994.

6. Hillman K, Bishop G, Bristow P. The crystalloid versus colloid controversy: present status. Ballieres Clin Anaesth 1997; 11: 1-13.

7. Mittermayr M, Streif W, Haas T, Fries D, Velik-Salchner C, Klingler A, et al. Effects of colloid and crystalloid solutions on endogenous activation of fibrinolysis and resistance of polymerized fibrin to recombinant tissue plasminogen activator added ex vivo. Br J Anaesth 2008; 100: 307-314.

8. Ruttmann TG, James MF, Aronson I. In vivo investigation into the effects of haemodilution with hydroxyethyl starch (200/0.5) and normal saline on coagulation. Br J Anaesth 1998; 80: 612-616.

9. Egli GA, Zollinger A, Seifert B, Popovic D, Pasch T, Spahn $D R$. Effect of progressive haemodilution with hydroxyethyl starch, gelatin and albumin on blood coagulation. $\mathrm{Br} J \mathrm{An}$ aesth 1997; 78: 684-689.

10. Niemi TT, Kuitunen AH. Artificial colloids impair haemostasis. An in vitro study using thromboelastometry coagulation analysis. Acta Anaesthesiol Scand 2005; 49: 373-378. similar designs $(7,25)$. RL was used as the maintenance fluid in all of our study groups, as commonly done in clinical practice as well as in studies using crystalloids vs colloids as perioperative fluids to maintain normovolemia. We did not think it was appropriate for the colloid groups to also receive colloid as their maintenance fluid because such a perioperative fluid strategy for major surgery patients is rarely encountered in clinical practice.

In the present study, RL, $6 \%$ HES (130/0.4) and 4\% JEL solutions given during major orthopedic operations changed TEG parameters, which, however, remained within normal limits. In major orthopedic procedures, which carry a high risk of thromboembolism, all perioperative infusion solutions can create undesirable effects in the hemostatic system. Perioperative TEG testing may be a useful tool to monitor patients with a high risk of thromboembolism.

11. Petroianu GA, Liu J, Maleck WH, Mattinger C, Bergler WF. The effect of in vitro hemodilution with gelatin, dextran, hydroxyethyl starch, or Ringer's solution on Thrombelastograph. Anesth Analg 2000; 90: 795-800.

12. Glidden PF, Malaska C, Herring SW. Thromboelastograph assay for measuring the mechanical strength of fibrin sealant clots. Clin Appl Thromb Hemost 2000; 6: 226-233.

13. Yee DL, Edwards RM, Mueller BU, Teruya J. Thromboelastographic and hemostatic characteristics in pediatric patients with sickle cell disease. Arch Pathol Lab Med 2005; 129: 760-765.

14. Mallett SV, Cox DJ. Thrombelastography. Br J Anaesth 1992; 69: 307-313.

15. Holliday MA, Segar WE. The maintenance need for water in parenteral fluid therapy. Pediatrics 1957; 19: 823-832.

16. Martin G, Bennett-Guerrero E, Wakeling H, Mythen MG, elMoalem $\mathrm{H}$, Robertson $\mathrm{K}$, et al. A prospective, randomized comparison of thromboelastographic coagulation profile in patients receiving lactated Ringer's solution, $6 \%$ hetastarch in a balanced-saline vehicle, or $6 \%$ hetastarch in saline during major surgery. J Cardiothorac Vasc Anesth 2002; 16: 441-446.

17. Janvrin SB, Davies G, Greenhalgh RM. Postoperative deep vein thrombosis caused by intravenous fluids during surgery. Br J Surg 1980; 67: 690-693.

18. Ruttmann TG, James MF, Finlayson J. Effects on coagulation of intravenous crystalloid or colloid in patients undergoing peripheral vascular surgery. $\mathrm{Br} J$ Anaesth 2002; 89: 226-230.

19. Butwick A, Carvalho B. The effect of colloid and crystalloid preloading on thromboelastography prior to Cesarean delivery. Can J Anaesth 2007; 54: 190-195.

20. Mardel SN, Saunders FM, Allen H, Menezes G, Edwards $\mathrm{CM}$, Ollerenshaw $\mathrm{L}$, et al. Reduced quality of clot formation with gelatin-based plasma substitutes. Br J Anaesth 1998; 80: 204-207.

21. Mishler JM. Synthetic plasma volume expanders - their pharmacology, safety and clinical efficacy. Clin Haematol 1984; 13: 75-92. 
22. Jones SB, Whitten CW, Despotis GJ, Monk TG. The influence of crystalloid and colloid replacement solutions in acute normovolemic hemodilution: a preliminary survey of hemostatic markers. Anesth Analg 2003; 96: 363-368.

23. de Jonge E, Levi M. Effects of different plasma substitutes on blood coagulation: a comparative review. Crit Care Med 2001; 29: 1261-1267.

24. Niemi TT, Suojaranta-Ylinen RT, Kukkonen SI, Kuitunen AH. Gelatin and hydroxyethyl starch, but not albumin, impair hemostasis after cardiac surgery. Anesth Analg 2006; 102: 998-1006.

25. Innerhofer $P$, Fries D, Margreiter J, Klingler A, Kuhbacher G, Wachter B, et al. The effects of perioperatively administered colloids and crystalloids on primary platelet-mediated hemostasis and clot formation. Anesth Analg 2002; 95: 858-865.

26. Mittermayr M, Streif W, Haas T, Fries D, Velik-Salchner C,
Klingler A, et al. Hemostatic changes after crystalloid or colloid fluid administration during major orthopedic surgery: the role of fibrinogen administration. Anesth Analg 2007; 105: 905-917.

27. Huttner I, Boldt J, Haisch G, Suttner S, Kumle B, Schulz H. Influence of different colloids on molecular markers of haemostasis and platelet function in patients undergoing major abdominal surgery. Br J Anaesth 2000; 85: 417-423.

28. Haas T, Preinreich A, Oswald E, Pajk W, Berger J, Kuehbacher $\mathrm{G}$, et al. Effects of albumin $5 \%$ and artificial colloids on clot formation in small infants. Anaesthesia 2007; 62: 1000-1007.

29. American Thoracic Society. Evidence-based colloid use in the critically ill: American Thoracic Society Consensus Statement. Am J Respir Crit Care Med 2004; 170: 1247-1259. 